\title{
Reception Customs in Qajar Dynasty of Iran from the Point of View of European Tourists
}

\author{
Hasan Asadi \\ Assistant Professor, Department of History and Sociology, University of Mohaghegh Ardabili, Ardabil, Iran \\ http://dx.doi.org/10.18415/ijmmu.v8i9.3004
}

\begin{abstract}
One of the first necessities of human life was nutrition and human beings from the very beginning tried to meet this need. Over time, the way food is prepared and how it is served has become a rich culture that varied among different nations. Attention has been formed to different geographical conditions and tastes. Perhaps the sensible food of one nation is not very pleasant for another nation. In this study, travel writers' perceptions of Iranian food culture have been written. Most reports indicate that Iranian food is not very diverse, but some have been introduced as very tasty, including rice. Iranian and kebab, which are very popular among Iranian dishes, have been reported from baking a variety of breads as well as very tasty and hearty Iranian syrups. Writers are located.
\end{abstract}

Keywords: Hospitalizing; Qajar; Food; Traveler; Iran

\section{Introduction}

Food customs of each nation are rooted in its culture. This culture includes their religious beliefs, values, and beliefs. Several food habits of this nation changed by Islam's arrival in Iran. The religion of Islam quickly took root in the hearts of the Iranian people and was able to influence most aspects of their lives. The effect of Islam, especially Shiism, reached its peak after the formation of the Safavid rule, and this effect was kept on until the Qajar dynasty. Qajar dynasty is a very important period in the history of Iran. A large number of European tourists came to Iran in the Qajar dynasty. In addition to political purposes, most of these European tourists paid attention to the anthropology and social history of the Iranian people and traveled to Iran to satisfy curiosity. Therefore, there are many treasures of travelogues in this historical period of Iran. European tourists have carefully observed many issues and tried to compare Iran with their own country. One of the issues that they did not neglect is food and eating habits. The food culture of the Iranian people has attracted the attention of a large number of tourists because it is a part of daily life and an integral part of the Iranian nation. The eating customs, cooking and preparing food and the manner of reception of guests are depicted in these travelogues with complete details and descriptions. Several tourists have discussed the material and spiritual aspects of Iranian food culture and the effect of Iranian religion on their eating customs. 


\section{Reception Customs in Iran}

One of the important customs among human beings, which is a sign of politeness and respect for each other, is the reception of guests, which is common among almost all nations by the formation of different customs and traditions among the nations. However, investigating different cultures usually shows that the eastern people have been more careful in reception customs and hospitality, and this issue is of particular importance among all nations. In addition, western travelers confirmed this point who has repeatedly visited the East especially Iran. They believe that Iranians are very hospitable people and pay special attention to the reception of travelers (Shail, 1989: 24). Iranians are very hospitable and showy simultaneously, so they often hospital their friends and relatives gorgeously (Droville, 1969: 96). Iranian hospitality has customs and traditions that are not the same in different places and its collection is welcomed (Oban, 1983: 78). This hospitality is observed equally among all people. There is no difference between the wealthy and the poor concerning hospitality among Muslims. Khan lives as simply a villager and never puts a morsel in her mouth unless he invites people around to eat. Barnes said: "I have personally participated in this charity with the wealthy and the poor many times because it is not enjoyable to eat far from the gathering of these people" (Barnes, 1994: 3-22). Iranian usually with improper economic situations hospitalize with generosity and warm heart (Wamberi, 1993: 170-169). There is more or less the same thing about the reception of guests and the types of food. Most of the news and content is very similar. Here, more details, and examples of reception levels and related regulations and etiquette are provided which are removed from the travelogue report. The dining room, also called the Divan, is a large rectangular room where the guests are gathered on a $3 \times 4 \mathrm{ft}$. (width and thickness) (lined) in the shape of a semicircle around the wall to hospitalize the guests (Drewville, 1969: 98). Dr. Wales says of the observance of the rules of etiquette that "accepting all formalities and observance of all these principles in the offerings were somewhat heavy and unacceptable for me, such as saying "Bismillah" while offering food to another, or when inviting a newcomer to sit next to them. At the begging of the feast I attended, I noticed that the host's behavior is different with entered guests to his house. These differences were in completely standing up in front of them, being more respectful, hurry to greet guests even in front of the house, and with great respect, bowing, respecting, and welcoming them to invite inside the home. The same behaviors happen while saying goodbye at the end of the feast, while for some guest, the host pretends not to see them and reject them even not say "Bismillah" while they sit and prevent offering and moving head. Therefore, later I noticed that in this country people use "You" instead of "you" to show honor and respect (Wales, 1989: 564).

Holding the large feasts by the aristocrats of the city has been really interesting, spectacular, and memorable. You are hospitalized with fruit and syrup, but no alcoholic drinks were seen in such a family party (Wales, 1989: 350).

In the Qajar dynasty, where communication with Europeans was widespread and more European travelers were present in Iran, the reception was expanded in the European style that was with the use of European equipment which was again to pay more respect to these guests, especially for guests with political missions. These characters have mentioned it in their travelogues. Ms. Schill said that "On the table inside the tent, there were some beautiful European dishes, including plates and glasses and china," who wrote relatively detailed accounts of her observations. The crown of all of them was six champagne bottles with silver caps along with twelve bottles of French and Spanish wines (Schill, 1989: 22). Since drinking alcoholic drinks was banned in Iran, it was only seen in special feasts with the presence of Europeans (Fraser, 1985: 197). It was especially Europeans in Iran while dealing with foreigners has sometimes been accompanied by dignity and respect and sometimes distance because of their impurity. For example, it was written in the description of the encounter that Khan, as soon as he knew that I was an Englishman, began to greet him, apologizing for not allowing him to sit down, and immediately taking me with him and offer sweets and a cup of wine and cold Shiraz (Layard, 1988: 60). The servants entered the parliament with the varieties of sweets that they had put on their heads. Alcoholic beverages were soon replaced and a set of rice and kebab was placed on the carpet instead. The guests circled the collections and brought a separate collection for me as a stranger. They brought them separately and I was happy not to eat 
with them on the same table because they contaminated the food with their dirty fingers and nails (Layard, 1988: 60).

In the same regard, De Gobino writes: Chairs sat on either side of a very long table arranged on large porcelain and crystal frames full of a variety of sweets and snacks (Dogubino, 2004: 93). The feast was like a European-style party that a large table was in the middle of the residence hall, although the number of guests was supposed to be twenty, a long table was completely covered under the table. They stood at the bottom of the porch or served tea and hookah trays in the hall. The table was arranged in a European style, a little in a French style, and more in an Iranian style with the help of European employees. Their flowers were also adorned in large quantities and the density of different and irregular colors was new to us (Dogobino, 2004: 168). I sat between them immediately and without compliments and waiting for an invitation in Isfahan and ate with them. Although they were Muslims, they were not upset by my presence at the table (Layard, 1988: 52).

However, the reception customs of the guests in the Iranian style had their own characteristics that were formed throughout history and were done with emphasis. The Persian-style tablecloth was spread on the floor and a servant brought a large tray full of rice and kebab, on the side of which a whole lamb was cooked and hidden (Herdvan, 1945: 88). Iranians usually spread the tablecloth on the floor and lean towards the tablecloth so that they can put food in their mouths. They only used fingers to take food and put it in their mouths that were a slow connection (Murray, 2006: 179).

Iranians usually sat on the floor because chairs were not yet very common in Iran in the Qajar dynasty and sitting like this was always difficult for Europeans who were not accustomed to it. we sat on two legs Like the Iranians to eat different foods for their pleasant including snacks, food cooked from butter, saffron, and sugar, and this jam was relay delicious (Flandin, 2536: 65: 65).

Ernest Ursel explained about the reception of his hot that "he spread a clean tablecloth on the table, not the red tablecloths that the Russians use throughout the week, but that was a real white linen tablecloth as was opened (Ursel, 2003: 134).

They sometimes prepared very so-called royal and luxurious dishes that surprised even the guests to please the guests and make them happy (Jackson, 1973: 118).

When the Iranians invited a foreigner to dinner, they told her that they had slaughtered a sheep. Barnes said that food is poured into wooden containers and each dish is placed in front of two people. The way of eating food is unique like its preparation (Barnes, 1994: 47).

Travel writers have paid less attention to breakfast in the description of Iranian food and meals, and most of the lunch and especially dinner meals have been mentioned. It may be because most feasts were for dinner or lunch or may Iranian pay less attention to the breakfast (Shale, 1989: 5-244).

Most descriptions are about lunch and dinner. Drewville writes: large tables are set in front of the guests at noon, then 5-6 servants bring the bleached copper basin to the sun. The guests wash their right hands and dry them with their handkerchiefs. Finally, the two guests place large degrees of sweets, biscuits, sweets, and fruit, respectively. Of course, bringing sweets and fruits has a luxurious and ceremonial aspect, and guests leave a piece of it more politely. Then, servants hastily remove the empty dishes in front of the guests because the guests are not so many masters of the principles of etiquette, so they empty their contents in the blink of an eye, and then they bring dinner (Drewville, 1969: 99). Lunch was a small bowl of yogurt with two boiled eggs cut in half and a bowl of porcelain that looked like porcelain of coffee. They put some fresh cheese in a similar dish and some grapes, cookies, and pieces of ice with the bread that they brought with us (Olivier, 1992: 31).

It was a custom for Iranian usually to bring a variety of snacks to the guests at dinners before dinners, such as sweets, nuts, and other snacks. The dishes were again offered to the guests before they 
leave the feast and the host said it is the supplement of the drinks and foods. This was also the custom in ancient Iran. Herodotus says that Iranians eat less non-liquid food but (dessert) spend a lot but not all (they do not put desserts on the table at the same time) (Jackson, 1973: 69). Dinner was paid more attention in the Qajar dynasty. Preparations of the most abundant, excellent, and best Iranian food, which they cooked pleasantly, followed by a dessert of sweets, which was also in the Iranian style (Fraser, 1985: 199).

Of course, Europeans were not all the same in taking advantage of receptions including bringing dinner to twenty guests and prepared a lot of food. However, there was not much difference in the color of the food such as rice with oil, chicken, skewers of mutton, soup, rice, kebab, and some pickles and fruits but there was no wine and intoxicants (Olivier, 1992: 90). They put our usual dinner on the table, a bowl full of skewers, yogurt bowls, and a few loaves of bread. After dinner, a cup of coffee will be served as a dessert. A samovar is also present and if anyone wants, he can drink a few cups of tea instead of coffee (Grote, 1990: 19). The guests gathered around the boiling samovar and enjoyed drinking tea, which they sweetened by dropping sugar cubes into syrup (Jackson, 1974: 100). At dinner, the servants entered with food sets on their heads (Lamerdon). The dinner contained rice and kebab and other fried meats and all kinds of syrups (Layard, 1988: 103).

The king also had his own characteristics in the Qajar dynasty reception, and it was customary for the king sometimes to visit the homes of certain personalities for a party, and these people would host the king with their own customs. When the king does not like to spend money, usually visits some people at a time. In these cases, among ordinary people and palace-living men, the king chooses someone who has the means and ability to offer an expensive gift. These meetings take place in two ways: a short rest at the home of some people but at home, some others accept a meal promise that the food is prepared by the chef and under special supervision (waiter) which had stamped with a king seal. The seal is removed exclusively in the presence of the king and at the time of eating. An army of cooks, cook apprentices, and a group of servants follows them from the palace to the house where the king is staying. However, spending all the necessary food and expenses from the host's pocket is one of the greatest honors that the king gives him. If he wants to give pride to the host, the king takes a bite of food with his fingers and sends it as a gift to the host. The host is full of pride at this time of taking a bite of food from the king and give tip to the bringer of the bite, and the who brings the morsel is in any position and dignity takes it with special dignity and puts it in her pocket (Serna, 1981: 90-89). There is also an example of Nasser al-Din Shah hosting foreign guests, which is largely a description of royal parties.

Fourier writes "rice and kebab with oil and saffron or various stews and lamb and cooked chicken and kebab skewers in which a piece of meat and a piece of tail is skewered one after the other, and grilled barley, sometimes with pomegranate or rye seeds in their bellies, with cooked eggplants and raw cucumber with salt and special fruits such as watermelon, melon, lavash bread, and ice water are the food and drinks of that feast, and we have to spend the same every day, whether at noon or night (Fourier, 2006: 3-52).

The Iranians held a relatively elaborate reception for the guests before the meal and especially for dinner. Grapes, cucumbers, radishes, almonds, and salt are placed on the table to enhance the appetite. Sometimes we listen to music by property owners for the entertainment of the guests and sometimes some people dance, but usually, the food is eaten in silence (Droville, 1969: 99-100).

Attendees were eating sweet baklava (a type of sweet) and enjoying the song (Herdvan, 1945: 91). By the end of the initial receptions including smoking a hookah, drinking coffee, and sitting in a room beside it, many fruits were brought along with sweets and ice cream (which the Iranians ate before eating). After eating all, they announce the main food is coming (James Moreau, 2006: 179).

The end of the party and reception of Iranians was sometimes accompanied by prayer and recitation of the Quran, but it was different depending on the occasion of the party and the location of the guests. One of the members in the meeting that was a high-level man sat in his place, take a serious look, read an AlFatiha surah, the first surah of the Quran, and others repeated each read verse. All opened their hands and 
say Amen (Fraser, 1985: 36-435). Three cups of the team and one Turkish coffee were distributed at the end of the meeting in the official visits. It is inferred that the session was ended before anyone say anything or leave. When someone asks, "do you let me leave?" the answer would be "don't mention it, it is your house, as you wish (Wishard, 1984: 188-122). The servant that is busy bringing tea, hookah, fruits, and drinks, and the party was ending in the early morning when the property owner brought the hookah with coffee, and then it was time to say goodbye (Wales, 1989: 351).

\section{Conclusion}

There have been always interactions between human in various forms since ancient times, and customs, culture, and knowledge of life, in general, has formed during these interactions and acquaintance with nations and attitudes. These acquaintances have highly related to the evolutionary process of human evolution. The interaction of nations with each other, made by the acquaintance with civilizations and has undeniably contributed to the expansion and evolution of the symbols of human civilization, has occurred, and these interactions have been being significant in almost all periods of human history since ancient to present time. However, the basic facilities of travel were very slow. Therefore, there was little communication. A dramatic change in means of transportation occurred by the development of European countries after the Renaissance, and especially with the Industrial Revolution. These writings are a clear example of reflecting the mentality of travel writers from the culture of different places. In addition, travel was greatly expanded, and it was after these trips that travelers and tourists reported these travels in the form of travelogues and various books have been written.

A brief research of travel writers' perceptions was said about Iranian food culture. Of course, these reports are just traveled writers' perceptions that are influenced by various factors. However, cultural differences and even cultural practices and customs among nations had and have always existed, and travel writers usually judge by the mentality they have about their culture and customs, and their criteria are usually habits and own behavior. Differences in taste in temperament and food taste are also a subset of Iranian and non-Iranian ideological and cultural differences. These differences can be seen in clothing, beliefs, etc. Food is also one of the important issues of these differences because various factors are involved in it such as geographical and climatic environment and economic and financial situation in the raw materials of food and how it is cooked and eaten. Even now, the food culture of nations differs from one another, and food or the way it is served may be pleasant for different tastes, although there is now much in common in the field of food, such as clothing. It is important to note that these differences should not be viewed with contempt. In this research, we often face writings in which Europeans speak with contempt and ridicule about Iranian food and eating manners. Of course, this case is not just true about food and is observed in many other European encounters with Iranian behavior and nature.

\section{References}

Barnes, Alex. (1987). Journey to Iran during the reign of Fath Ali Shah, translated by Hassan Soltanifar, Mashhad: Astan Quds Razavi publication.

Benjamin, Green Wheeler. (1984). Iran and Iranians, translated by Mohammad Hossein Kordbacheh, Tehran: Javidan.

Fourier. (2006). Three years in the court of Iran, translated by Abbas Iqbal, Tehran: Elm publications.

Fraser, James Bailey. (2006). translated by Manouchehr Amiri, Tehran: Toos Publications.

Gobineau. (2004). Three Years in Asia, Translated by Abdolreza Houshang, Tehran: Qatreh Publications. 
Jackson. (1973). Iran in the Past and Present, translated by Manouchehr Amiri, Tehran: Franklin Publications.

Jones, Sirhard Ford. (2007). Memoirs of Sirhard Ford Jones, translated by Salehi Allameh, Tehran: Third Edition.

Layard, Sir Austin Henry. (1988). Layard's travelogue, translated by Mehrab Amiri, Tehran: Vahid Publications.

Moriah, James. (2006). Journey to Iran, Armenia, Asia Minor, translated by Abolghasem Serri, Tehran: Toos Publications.

Oben, Eugene. (1983). Iran Today, translated by Ali Asghar Saeedi, Tehran: Naghsh Jahan Publications.

Olivier. (1993). Olivier Travelogue, translated by Mohammad Taher Mirza, Tehran: Etela'at Publications.

Serna, Carla. (1983). People and Religions in Iran, translated by Ali Asghar Saeedi, Tehran: Naghshe Jahan Publications.

Shale, Lady. (1989). Lady Shale's Memoirs, translated by Hossein Torabian, Tehran: Nashre No Publications.

Ursel, Ernst. (2003). Travelogue of the Caucasus and Iran, translated by Ali Asghar Saeedi, Tehran: Institute of Humanities and Cultural Studies.

Wambery, Arminius. (1993). The Journey of the False Darwish, translated by Mohammad Hossein Aria, Tehran: Scientific and Cultural Publications.

Wishard, John. (1983). Twenty Years in Iran, Translated by Ali Pirnia, Tehran: Novin Publications.

\section{Copyrights}

Copyright for this article is retained by the author(s), with first publication rights granted to the journal.

This is an open-access article distributed under the terms and conditions of the Creative Commons Attribution license (http://creativecommons.org/licenses/by/4.0/). 